\title{
Simulation of the Martian Atmosphere Using a CCSR/NIES AGCM
}

\author{
Takeshi KURODA, Naohisa HASHIMOTO, Daisuke SAKAI and Masaaki TAKAHASHI \\ Center for Climate System Research, University of Tokyo, Tokyo, Japan
}

(Manuscript received 29 March 2002, in final form 3 September 2004)

\begin{abstract}
The new simulation of Martian general circulation based on CCSR/NIES AGCM has been performed and the numerical results analyzed. We attempt to reproduce the atmospheric states of Mars which have been observed by the Mars Global Surveyor, and Viking by introducing three kinds of time- and latitudedependent dust opacity scenarios which are made to be consistent with the past observational results, as the observed dust distribution during spring and summer in south hemisphere varies largely at each year and so does observed atmospheric conditions. The model with TES2 dust scenario, which is the dust distribution based on the observation by the Mars Global Surveyor in 1999, generally reproduces distributions of temperature and zonal wind observed by the Mars Global Surveyor in 1999, though the temperature tends to be lower at high altitude. The maximum value of $\mathrm{CO}_{2}$ ice thickness at polar regions relatively reproduces the observation, but the edge of the northern and southern seasonal caps are outside of the observational results during spring, which results in lower surface pressure especially in northern spring. Annual variations of the amplitudes of the diurnal and semidiurnal tide are qualitatively comparable between our model with VIK1 dust scenario, which is the dust distribution based on the observation by Viking Orbiter in 1977, and observation by Viking Lander 1 in 1977. The baroclinic waves with consistent periods, wavenumbers and phase speeds with observational results by Viking Lander 2 in 1977 are reproduced in the autumn, though in the winter, during the second dust storm, and in the spring, the phase speeds are faster than observation.
\end{abstract}

\section{Introduction}

Atmospheric conditions on Mars are quite different from those of the Earth. The dominant atmospheric component is $\mathrm{CO}_{2}(95.3 \%$ of the atmosphere) and there is little water. The averaged surface pressure on Mars is about $6.1 \mathrm{hPa}$, and surface pressure varies annually with the range of $25 \%$ of the averaged pressure, because the atmospheric component of $\mathrm{CO}_{2}$ condenses at polar regions (e.g. James et al. 1992).

Dust in the atmosphere plays very important roles in Martian meteorology, as well as radiative effects of $\mathrm{CO}_{2}$. Atmospheric temperature and structure relate closely to dust opacity in

Corresponding author and present affiliation: Takeshi Kuroda, Max-Planck-Institut für Sonnensystemforschung, Max-Planck-Straße 2, D-37191 Katlenburg-Lindau, Germany.

E-mail: kuroda@linmpi.mpg.de

(C) 2005, Meteorological Society of Japan the atmosphere. Especially in southern spring and summer the dust storm activity becomes strong in every Martian year, because Mars' eccentricity (0.0934) is large and perihelion of Mars is near the southern summer solstice (aerocentric longitude $L_{s}=250^{\circ}$ at periherion, where $L_{s}=90^{\circ}$ and $L_{s}=270^{\circ}$ correspond to northern and southern summer solstices, respectively). The amount of insolation at southern spring and summer is about 1.3 times larger, so the atmospheric convection becomes stronger than that in northern spring and summer. The scale of the dust storm which occurs in this period differs in each year (from regional to planet-encircling), and hence atmospheric temperature has strong year-to-year variability according to the dust opacity. In contrast, in northern spring and summer the dust opacity and air temperature are lower and exhibit high year-to-year repeatability. Ob- 
served zonal-mean infrared $(9 \mu \mathrm{m})$ dust opacity at the equator, using a modified version of the retrieval scheme by Martin (1986), is around 0.05 in northern spring and summer at each year observed by Mariner 9, Viking Orbiters and Mars Global Surveyor (MGS). In southern spring and summer the observed maximum dust opacity at each year varies between 0.25 and 1.4 at the equator, according to the scales of occurred dust storms (Liu et al. 2003).

In the northern and southern hemispheres, $\mathrm{CO}_{2}$ begins to condense out of the atmosphere at high latitudes in autumn as the regions encounter increasing darkness, depositing a thin veneer of dry ice, and the surface frost zone expands to mid-latitudes in late winter. In early spring, as the surface receives more sunlight, surficial $\mathrm{CO}_{2}$ begins to sublime and the frost zone retreats to high latitudes. The variation of elevation due to $\mathrm{CO}_{2}$ polar cap observed by the Mars Orbiter Laser Altimeter (MOLA) on the MGS is $1.0-1.5 \mathrm{~m}$ in both poles within a year (Smith et al. 2001b). In north polar regions the seasonal cap regresses with remaining relatively circular and uniform shape during northern late winter to spring. The recession of cap edge latitude versus $L_{s}$ during this time is roughly represented as a linear function, though there is some slight interannual variability, by the observations of the Hubble Space Telescope (HST) and the Mars Orbiter Camera (MOC) on the MGS (Cantor et al. 1998; James and Cantor 2001; Kieffer and Titus 2001). In contrast, the south polar cap regresses axiasymmetrically, especially after $L_{s}=240^{\circ}$ (e.g. Kieffer et al. 2000).

The existence of large thermal tides plays an important role in Martian meteorology. Since the convective thermal drive on Mars is about ten times as effective as the diurnal forcing of Mars (per unit mass), because the atmosphere is very thin and has a very small heat capacity, the tidal response may be expected to scale up accordingly. In addition, the Martian atmosphere is strongly heated internally because of suspended dust, leading to a further enhancement of the tides, the enhancement varying with the dust load (Leovy 1979). In Viking observations, the amplitudes of diurnal and semidiurnal components of the surface pressure variation were around 1 percent of the mean pressure at Lander $1\left(\mathrm{VL} 1,22.5^{\circ} \mathrm{N}, 48^{\circ} \mathrm{W}\right)$ and
0.5 percent at Lander $2\left(\mathrm{VL} 2,48^{\circ} \mathrm{N}, 226^{\circ} \mathrm{W}\right.$ ) when it is without global dust storms, and they became 3-4 times larger during the global dust storms (Leovy and Zurek 1979; Tillman 1988). Also about wind speeds, it was observed by VL2 that diurnal and semidiurnal variations became large during global dust storms (Leovy and Zurek 1979; Leovy 1981).

In northern midlatitude winter, the oscillations with the period of longer than $1 \mathrm{Sol}$ (a Mars solar day equal 88,775 seconds) are also conspicuous, as obviously seen from the annual variation of daily averaged pressure in VL2 (Barnes 1980, 1981; Tillman 1988). It is recognized that these oscillations are probably due to the passage of baroclinic waves. Some papers (e.g. Barnes 1980, 1981; Sharman and Ryan 1980) investigated them using spectral analyses. By the analyses of Barnes (1980), there are 6-8 and around 3 Sols of dominant periodicities in surface pressure, meridional wind, zonal wind and temperature data in the autumn and spring of 1977. According to the calculation from the amplitudes of pressure, and meridional wind perturbation in the supposition of the geostrophic relation, they correspond to approximately 2 and 4 wavenumbers and $10-16 \mathrm{~m} \mathrm{~s}^{-1}$ of the phase speeds. These wavenumbers and phase speeds calculated are generally consistent with theoretical expectations for baroclinic waves on Mars (Leovy 1969, 1979) and with the results of early Martian GCMs (Leovy and Mintz 1969; Pollack et al. 1981). In the winter of this year, soon after the "1977b" global dust storm by Tillman (1988), only the 6-8 Sols of periodicity was dominant and the phase speeds became much slower.

In studying the Martian atmospheric science, General Circulation Models (GCMs) have been used. GCMs are useful when we want to study global circulation and inspect the observational results. Comprehensive general circulation modeling of the Martian atmosphere began with Leovy and Mintz (1969), who successfully adapted the terrestrial GCM of the University of California, Los Angeles (UCLA) to Martian conditions. After this, several research groups have developed Martian GCMs and many researches have been done at NASA/Ames Research Center, French Laboratory of Dynamic Meteorology (LMD)/Atmospheric, Oceanic and Planetary Physics (AOPP) in Oxford, Geophys- 
ical Fluid Dynamic Laboratory (GFDL), and so on.

The NASA/Ames Martian GCM has been used as the simulator of $\mathrm{CO}_{2}$ polar processes and atmospheric dynamics in Mars' atmosphere (Pollack et al. 1990, 1993; Barnes et al. 1993, 1996; Haberle et al. 1993), and also used for interpretation of the Mars Pathfinder experiment (Haberle et al. 1999). LMD Martian GCM firstly simulated a full Martian year without any forcing other than insolation and topography (Hourdin et al. 1993, 1995) and was also able to reproduce the seasonal and transient pressure variations observed by the Viking Landers (Hourdin et al. 1995; Collins et al. 1996). After collaborating with AOPP, they have attempted to simulate up to the altitude of $120 \mathrm{~km}$ including non-LTE processes of $\mathrm{CO}_{2}$ radiation (Forget et al. 1999; Lewis et al. 2001). GFDL Martian GCM has been used to study the role of thermal tides (Wilson and Hamilton 1996) and re-examine the Viking IRTM temperature observation (Wilson and Richardson 2000). These major Martian GCMs include surface parameters (topography, albedo and thermal inertia), $\mathrm{CO}_{2}$ condensation-sublimation processes, $\mathrm{CO}_{2}$ radiation codes (both thermal infrared and near-infrared absorption) and radiative effects of dust.

In this paper we present the performances of a new Martian atmospheric GCM based on a CCSR/NIES AGCM. We have introduced the important physical processes to make Martian GCM, which are $\mathrm{CO}_{2}$ condensation-sublimation and the effect of $\mathrm{CO}_{2}$ near-infrared absorption of solar radiation, from the GCM for terrestrial atmosphere. Moreover, we changed the surface parameters, radiative parameters of dust (refractive indices and particle size distribution) to fit the observational results of Mars. The present Martian model is described in Section 2. Numerical results and a summary are presented in Section 3 and 4, respectively.

\section{Model description}

The model in this study used a Center for Climate System Research (CCSR), University of Tokyo/National Institute for Environmental Studies (NIES), atmospheric general circulation model (AGCM). The basic features of CCSR/NIES AGCM are presented by Numaguti (1993), and newly implemented physical processes are discussed by Numaguti et al. (1995). In this simulation, we changed parameters of the AGCM to adjust the environment of Mars as follows: Radius of the planet $(3397 \mathrm{~km})$, acceleration of gravity $\left(3.72 \mathrm{~m} \mathrm{~s}^{-2}\right)$, pure $\mathrm{CO}_{2}$ atmospheric specific heat at constant pressure $\left(735.9 \mathrm{~J} \mathrm{~K}^{-1} \mathrm{~kg}^{-1}\right)$, atmospheric gas constant (188.86 $\mathrm{J} \mathrm{K}^{-1} \mathrm{~kg}^{-1}$ ), solar constant $\left(589.2 \mathrm{~W} \mathrm{~m}^{-2}\right)$, component of atmosphere $\left(\mathrm{CO}_{2}\right.$ : $95.3 \%, \mathrm{O}_{2}: 0.13 \%$ ), orbital elements (eccentricity: 0.0934, angle of equator inclination: $25.19^{\circ}$ ), and calendar (669 Sols a year and 88,776 seconds a day). This model does not include water processes, but includes dry convective adjustments.

\subsection{Dynamics}

The basic equations are three-dimensional hydrostatic primitive equations on sphere with normalized pressure $(\sigma)$ coordinate. The horizontal resolution is set at about $5.6^{\circ}$ longitude by $5.6^{\circ}$ latitude (T21, i.e., triangular truncation with wavenumber 21). The vertical resolution is 33 layers with $\sigma$-levels, and the top of the model is about $80 \mathrm{~km}$ at height.

Rayleigh friction is imposed near the upper boundary. The Rayleigh friction coefficience depends on $\sigma$-level as shown in Fig. 1. The damping time near the top boundary is 0.5 day.

\subsection{Surface parameters}

Topography, albedo, and thermal inertia data for Mars surface are introduced. Topogra-

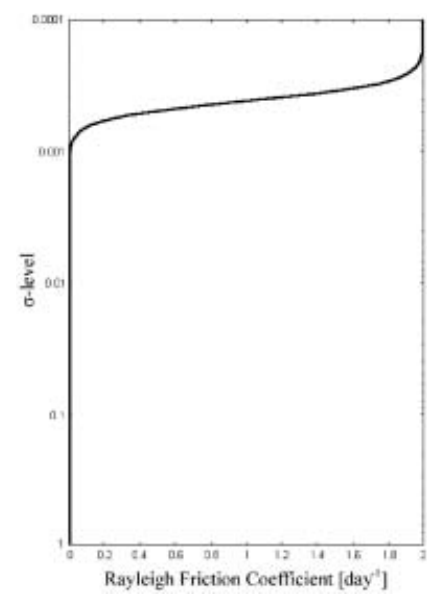

Fig. 1. $\sigma$-level altitude distribution of Rayleigh friction coefficient used in this model. 


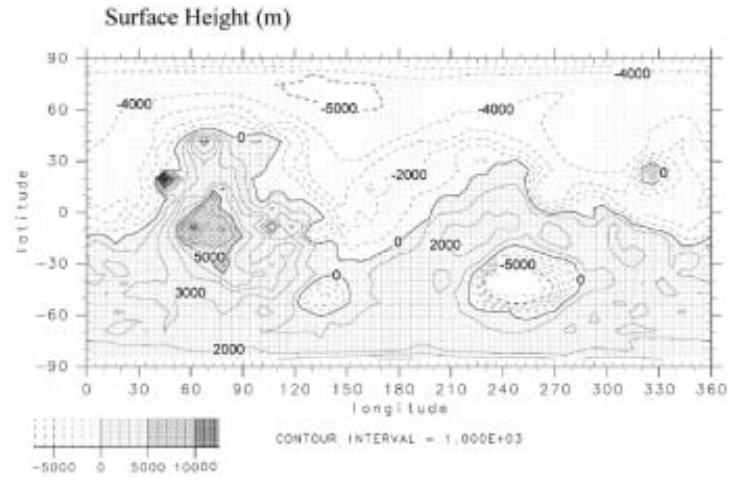

Fig. 2. Latitude-longitude distribution of topography used in this model [m].

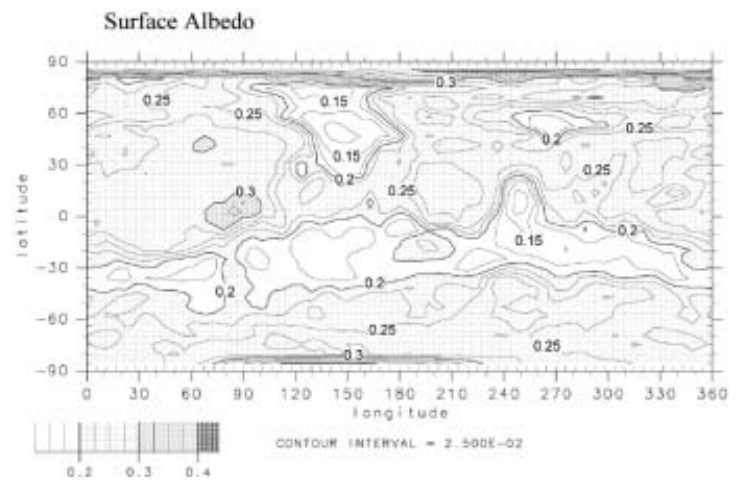

Fig. 3. Latitude-longitude distribution of surface albedo data used in this model.

phy used in the model is based on the observations of the Mars Orbiter Laser Altimeter (MOLA) on the Mars Global Surveyor (MGS) (Smith et al. 1999). The data set of surface albedo and surface thermal inertia is the same as that of LMD/AOPP Martian GCM (Forget et al. 1999; thermal inertia data is fixed in Forget et al. 2001). The topography and surface albedo are averaged to the model's horizontal grid, as shown in Figs. 2 and 3. Surface thermal conductivity and heat capacity are calculated from the averaged surface thermal inertia (Fig. 4) referring to Mellon (2001) and Larsen and Dahl-Jensen (2000), and introduced in the model.

\subsection{Radiation}

\section{3.a $\mathrm{CO}_{2}$ gas}

The treatment of absorption and emission by the strong $\mathrm{CO}_{2} 15 \mu \mathrm{m}$ band is done by a radia-

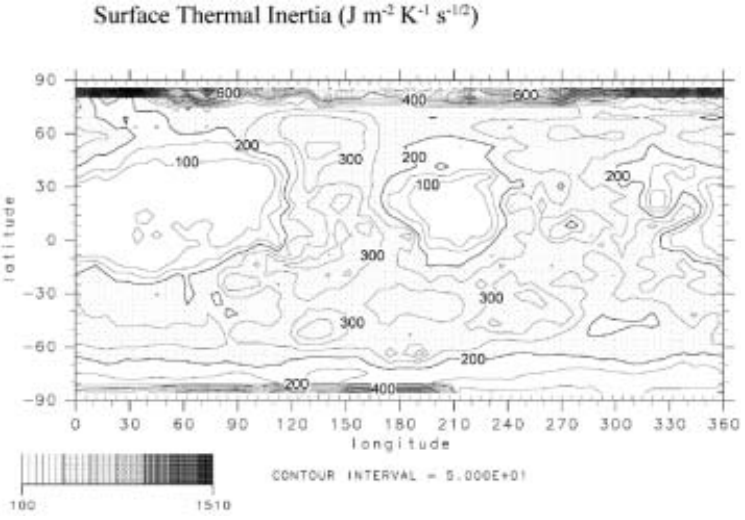

Fig. 4. Latitude-longitude distribution of surface thermal inertia data used in this model $\left[\mathrm{J} \mathrm{m}^{-2} \mathrm{~K}^{-1} \mathrm{~s}^{-1 / 2}\right]$.

tion scheme based on the $k$-distribution and the two-stream discrete ordinate method (Nakajima and Tanaka 1986). The scheme introduces the $\mathrm{CO}_{2}$ radiative effects in wavenumber 550 to $770 \mathrm{~cm}^{-1}$ (wavelength 13.0 to $18.2 \mu \mathrm{m}$ ) dividing 9 channels.

The effects of atmospheric heating due to absorption of solar radiation in the nearinfrared band are included by calculating the heating rate by a simple analytical formula which is used in LMD/AOPP Martian GCM (Forget et al. 2003). The formula is based on the one-dimensional model calculation of Lopez-Puetras and Lopez-Valverde (1995).

In both schemes a Local Thermodynamic Equilibrium (LTE) is assumed at all altitudes as non-LTE processes are effective above the altitude of $\sim 80 \mathrm{~km}$ (Lopez-Valverde et al. 1998), not treated in our model.

\section{3.b Dust}

The treatment of absorption, emission and scattering by atmospheric dust is also done by the scheme of Nakajima and Tanaka (1986). In this model, refractive indices and particle size distribution of the dust are changed to fit the up-to-date research results of Martian dust. The refractive indices data are made referring to Ockert-Bell et al. (1997) at the wavelength of less then $5 \mu \mathrm{m}$, montmorillonite $219 \mathrm{~b}$ data in Toon et al. (1977) at the wavelength of between 5 and $17 \mu \mathrm{m}$, and constant values in Forget (1998) at the wavelength of more than $17 \mu \mathrm{m}$. Resulting complex refractive indices are shown in Fig. 5. The particle size distribution is given 


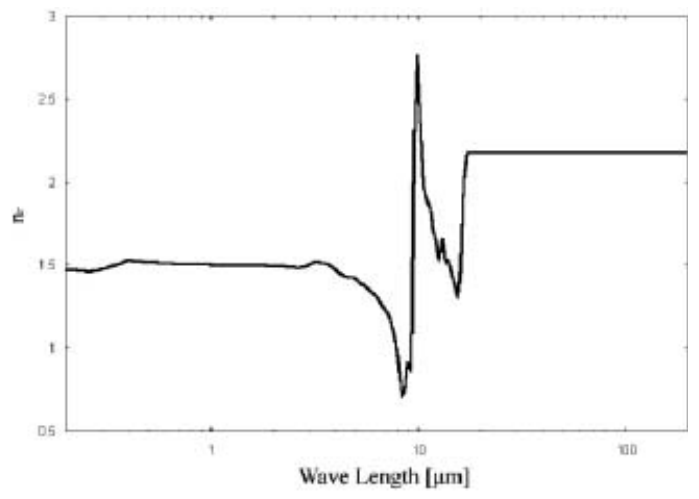

(a)

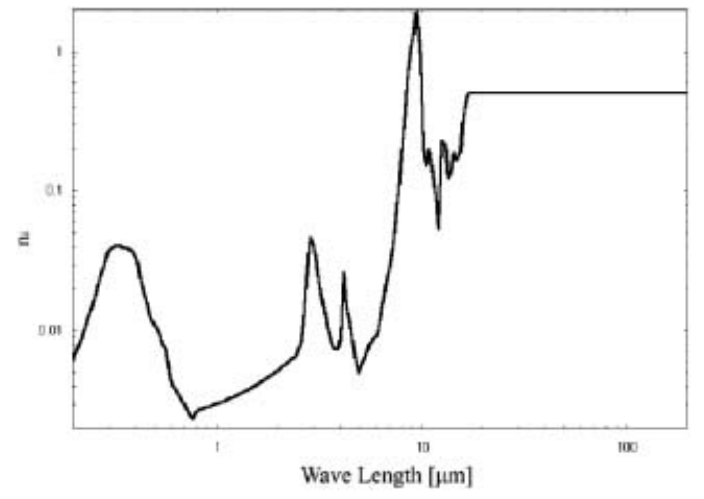

(b)

Fig. 5. Wavelength distributions of (a) Real and (b) imaginary part of refractive indices of Martian dust used in this model.

by Tomasko et al. (1999), which uses modified gamma function with an effective radius of $1.6 \mu \mathrm{m}$ and an effective variance of 0.2 , which results in the mode radius of $0.64 \mu \mathrm{m}$, as shown in Fig. 6. These settings of the dust parameters are the same as those in the retrieval scheme used in Liu et al. (2003), which calculates dust opacity from the observational data.

\subsection{Atmospheric dust distribution}

We made three dust distribution scenarios which vary with time and latitude, named TES2, TES3 and VIK1 dust scenarios, to reproduce the distribution observed by MGS and Viking. TES2 dust scenario is based on the retrieved dust opacity of TES Year 2 (Year 1999) by Liu et al. (2003), and TES3 and VIK1 dust

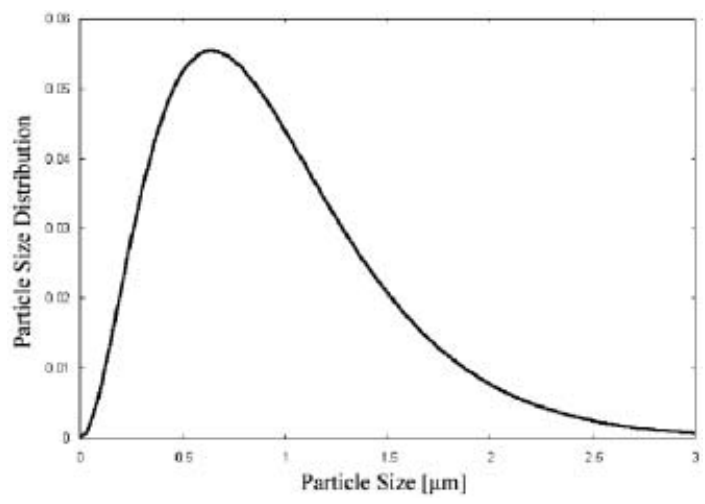

Fig. 6. Particle size distribution of Martian dust used in this model. scenarios are based on TES Year 3 (Year 2001) and Viking Year 1 (Year 1977) in the same paper, respectively. The observational results of dust opacity by Smith et al. (2001a), Smith et al. (2002) and Martin and Richardson (1993) are also taken into consideration for determining dust distributions in TES2, TES3 and VIK1 scenarios, respectively.

We used the framework of the dust scenarios of LMD/AOPP Martian GCM (Lewis et al. 2001) which calculates the optical depth of the equator, south pole and north pole by a function of aerocentric longitude $L_{s}$. When a global dust storm occurs, the increasing rate of dust opacity is rapider than the decreasing rate during decay, according to observation. To reproduce this better, we used a hyperbolic tangent transition when the dust opacity increases. The summary is as follows;

$$
\begin{aligned}
& \text { If } L_{s}<L_{s 1}, \\
& \begin{aligned}
\tau_{*}\left(L_{s}\right)= & 0.05+\frac{\tau_{\max }-0.05}{2} \\
& \times\left[1+\tanh \left\{\left(L_{s}-L_{s 0}\right) * \alpha\right\}\right]
\end{aligned}
\end{aligned}
$$

If $L_{s} \geq L_{s 1}$

$\tau_{*}\left(L_{s}\right)=0.05+\left(\tau_{\max }-0.05\right)\left\{\cos \left(\left(L_{s}-L_{s 1}\right) / 2\right)\right\}^{\beta}$

where $\tau_{*}$ represents the infrared $(9-10 \mu \mathrm{m})$ dust opacity at $7 \mathrm{hPa}$. The factors $\tau_{\max }$ is the maximum dust opacity in each regions, $L_{s 0}$ is the aerocentric longitude when dust storms occur most intensely, $L_{s 1}$ is the aerocentric longi- 
Table 1 Values of the factors used in formulas (1) (6) for deciding time-latitude profiles of three dust scenarios used in this paper. N, EQ and $\mathrm{S}$ correspond to the factors for calculating $\tau_{N}, \tau_{e q}$ and $\tau_{S}$, respectively. In VIK1 scenario two major dust storms occur, so the optical depth $\tau$ is defined by $\tau=\max \left[\tau_{1}, \tau_{2}\right]$, where $\tau_{1}$ and $\tau_{2}$ are the optical depths of VIK1(1) and VIK1(2), respectively, in the table.

\begin{tabular}{|c|c|c|c|c|c|c|c|c|c|c|c|c|}
\hline & \multicolumn{3}{|c|}{ TES2 } & \multicolumn{3}{c|}{ TES3 } & \multicolumn{3}{c|}{ VIK1(1) } & \multicolumn{3}{c|}{ VIK1(2) } \\
\hline & $\mathrm{N}$ & EQ & $\mathrm{S}$ & $\mathrm{N}$ & $\mathrm{EQ}$ & $\mathrm{S}$ & $\mathrm{N}$ & $\mathrm{EQ}$ & $\mathrm{S}$ & $\mathrm{N}$ & EQ & $\mathrm{S}$ \\
\hline$\tau_{\max }$ & 0.1 & 0.2 & 0.5 & 0.1 & 0.7 & 1.0 & 0.1 & 0.6 & 0.5 & 0.2 & 1.3 & 1.5 \\
$L_{s 0}$ & $225^{\circ}$ & $220^{\circ}$ & $215^{\circ}$ & $210^{\circ}$ & $190^{\circ}$ & $192^{\circ}$ & $216^{\circ}$ & $206^{\circ}$ & $206^{\circ}$ & $280^{\circ}$ & $272^{\circ}$ & $272^{\circ}$ \\
$L_{s 1}$ & $240^{\circ}$ & $235^{\circ}$ & $235^{\circ}$ & $230^{\circ}$ & $205^{\circ}$ & $205^{\circ}$ & $230^{\circ}$ & $215^{\circ}$ & $218^{\circ}$ & $295^{\circ}$ & $283^{\circ}$ & $283^{\circ}$ \\
$\alpha$ & 12 & 15 & 8 & 10 & 18 & 22 & 12 & 22 & 22 & 12 & 18 & 18 \\
$\beta$ & 30 & 30 & 20 & 20 & 20 & 15 & 30 & 10 & 10 & 30 & 23 & 23 \\
\hline
\end{tabular}

tude when the dust opacity begins to decrease, and $\alpha$ and $\beta$ are the factors of increasing and decreasing rates of dust opacity. Larger $\alpha$ represents rapider increase of dust opacity, and larger $\beta$ represents faster decay. The values of these factors used in each dust scenarios are shown in Table 1. From $\tau_{*}$ calculated at the equator, south pole and north pole, $\tau_{e q}, \tau_{S}$ and $\tau_{N}$, the infrared optical depth at $7 \mathrm{hPa}, \tau$, on any point of the planet is interpolated using a hyperbolic tangent transition in northern hemisphere and a sine transition in southern hemisphere;

$$
\begin{aligned}
& \tau\left(\phi, L_{s}\right)=\tau_{N}+\frac{\tau_{e q}-\tau_{N}}{2} \\
& \times\left\{1+\tanh \left(5\left(45^{\circ}-\phi\right)\right)\right\} \quad(\phi>0) \\
& \tau\left(\phi, L_{s}\right)=\tau_{S}+\frac{\tau_{e q}-\tau_{S}}{2} \\
& \quad \times\left\{1+\sin \left(2\left(45^{\circ}+\phi\right)\right)\right\} \quad(\phi<0)
\end{aligned}
$$

where $\phi$ is the latitude.

The vertical distribution of dust is calculated according to the following formula as referred in Forget et al. (1999) and Lewis et al. (1999);

$Q=Q_{0} \exp \left\{0.007\left(1-\max \left[\left(\frac{p_{0}}{p}\right)^{70 / z_{\max }}, 1\right]\right)\right\}$

$z_{\max }\left(\phi, L_{s}\right)=60+18 \sin \left(L_{s}-160^{\circ}\right)-22 \sin ^{2} \phi$

where $z_{\max }$ is the cut-off altitude of the dust $[\mathrm{km}], p$ is the pressure, $p_{0}$ is the standard pressure $(7 \mathrm{hPa})$, and $Q$ and $Q_{0}$ are the dust mixing ratio at the pressure levels $p$ and $p_{0}$. These formulas are derived from considerations of particle sedimentation and eddy mixing by Conrath (1975), and deduced top altitude of the dust layers from the analysis by Anderson and Leovy (1978) and Jaquin et al. (1986).

The time-latitude profiles of each dust scenarios are shown in Fig. 7.

\subsection{Condensation and sublimation processes of $\mathrm{CO}_{2}$}

$\mathrm{CO}_{2}$ condensation and sublimation processes are included in this model, referring to Forget et al. (1998). The condensation temperature of $\mathrm{CO}_{2}$ is given by the Clausius-Clapeyron relation (Hourdin et al. 1995). When the atmospheric temperature predicted from the $\mathrm{dy}$ namical and radiative cooling rates is below the condensation temperature, the condensation occurs and the latent heat is released to keep the atmospheric temperature to the condensation temperature. The condensed $\mathrm{CO}_{2}$ falls to the surface immediately, then the potential energy released by ice falling and the energy used to heat the ice to the condensation temperature of lower level are taken into account in calculating the mass of condensed $\mathrm{CO}_{2}$. The condensation on the ground is also considered as well as in the atmosphere. The loss of atmospheric mass due to condensation (or conversely the gain due to sublimation) is taken into account by modifying the surface pressure to conserve the total mass of $\mathrm{CO}_{2}$ (caps + atmosphere). Values of surface albedo and thermal conductivity are set to 0.65 and $0.5 \mathrm{~W} \mathrm{~m}^{-1} \mathrm{~K}^{-1}$ when the surface is covered with $\mathrm{CO}_{2}$ ice. 

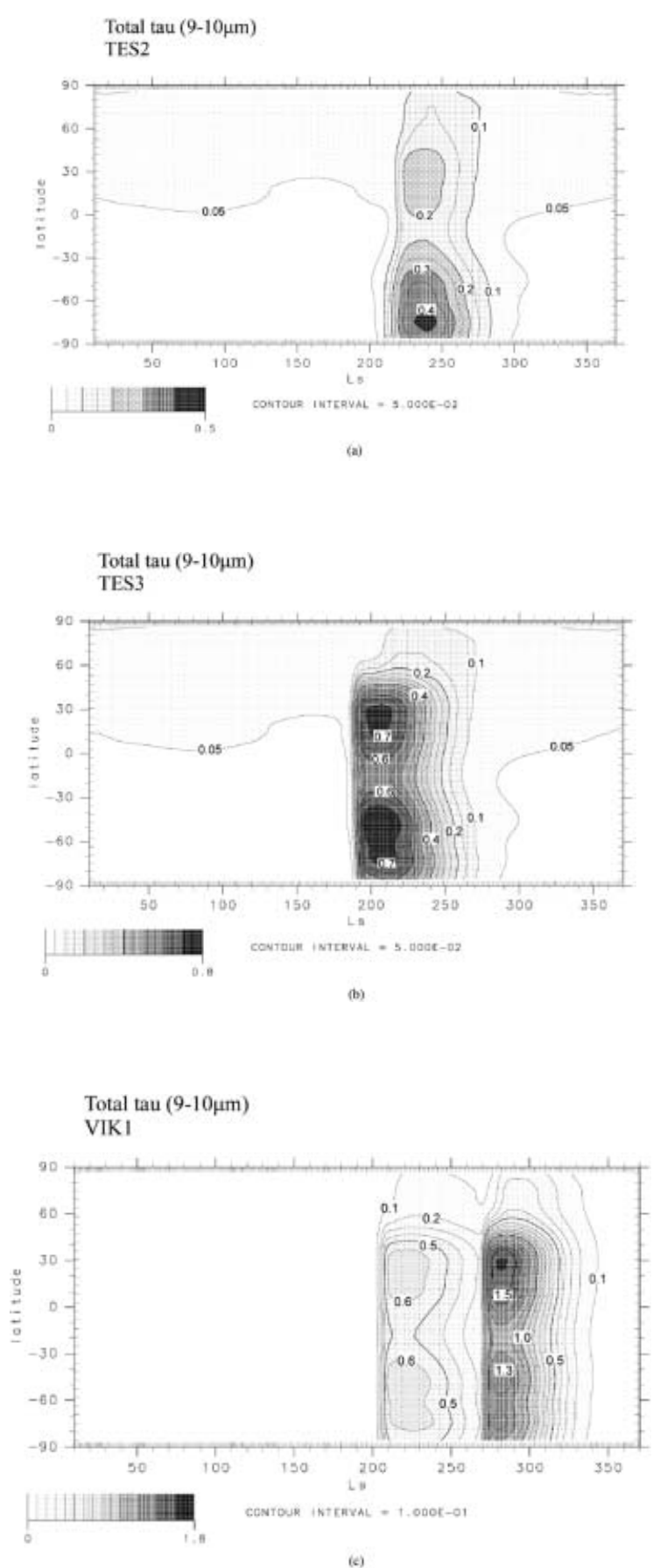

Fig. 7. Time-latitude profiles of the zonal-mean dust optical depth in infrared wavelength $(9-10 \mu \mathrm{m})$ at surface in this model; (a) TES2, (b) TES3, (c) VIK1 dust scenarios.

\section{Numerical results}

We ran the models with the three kinds of dust scenarios described in Section 2 from northern spring equinox for three Martian years, with an initial state of isothermal conditions $(240 \mathrm{~K})$, a constant surface pressure of $8 \mathrm{hPa}$ and no $\mathrm{CO}_{2}$ ice. We used the third year simulation results for numerical results in the following subsection.

\subsection{Distribution of temperature and wind 3.1.a Seasonal variations in the model with TES2 dust scenario}

Figure 8 shows the numerical results of zonal-mean temperature in the model with TES2 dust scenario around northern autumn equinox $\left(L_{s}=175^{\circ}-185^{\circ}\right)$ and winter solstice $\left(L_{s}=265^{\circ}-275^{\circ}\right)$, respectively. Note that this figure represents the mean values of day and night time. The differences of temperature between daytime (local time $\sim 1400$ ) and nighttime (local time $\sim 0200$ ) are less than $10 \mathrm{~K}$, except near the surface and above the altitude of $0.1 \mathrm{hPa}$ around the point right under the sun, where the absorption of solar radiation in the $\mathrm{CO}_{2}$ near-infrared band is the most effective. The TES retrievals correspond to a very low vertical resolution since the weighting function is very broad (Conrath et al. 2000), so the TES thermal structure may have large uncertainties, especially near the surface.

Within this context, the model results are roughly consistent with daytime observational results in TES Year 2 (Smith et al. 2003) below the altitude of $0.1 \mathrm{hPa}$, except two conscious differences. One is $\sim 20 \mathrm{~K}$ higher temperature around the surface of the north pole at autumn equinox. This warmer autumn north pole temperature is also seen in the result of LMD/ AOPP model (Forget et al. 2001). The radiometric calibration of the TES instrument may cause the errors of more than $5 \mathrm{~K}$ in the cold polar regions (Conrath et al. 2000). In addition to this, there may be some characteristics of the models to prevent the cooling of polar regions as the daylight time becomes shorter. The other is $\sim 10 \mathrm{~K}$ higher temperature above southern polar regions and northern midlatitude. This seems to be because the thicker dust opacity in the southern hemisphere, and larger meridional circulation and adiabatic heating invoked by the heating by dust. Liu et al. (2003) 


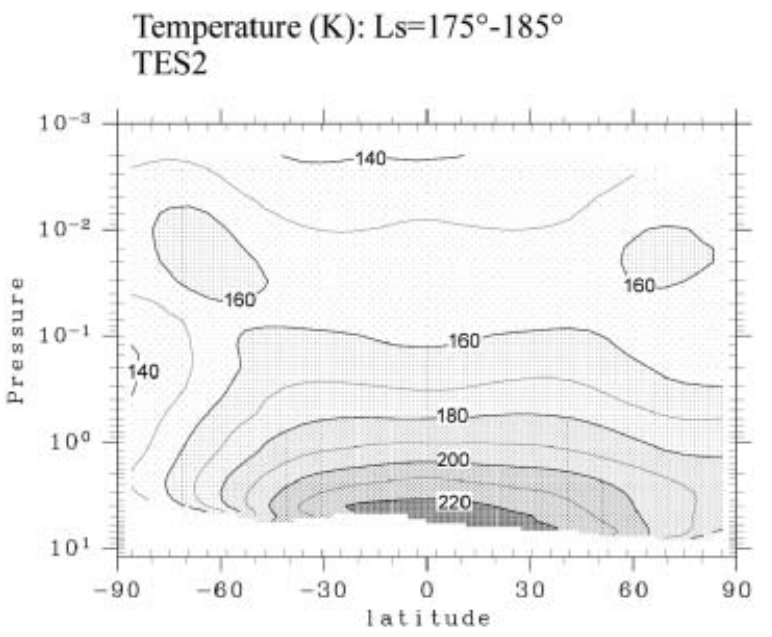

(a)

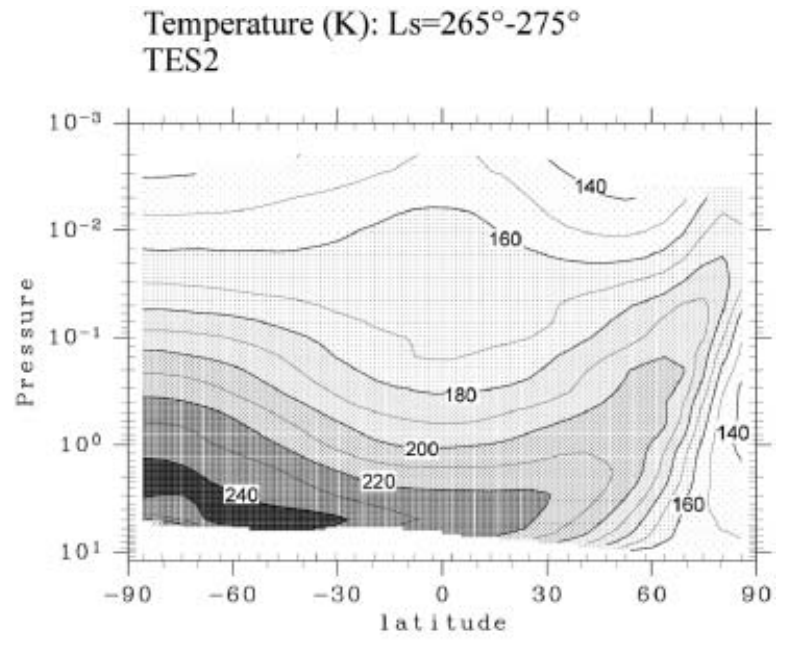

(b)

Fig. 8. Numerical results of time- and zonal-mean atmospheric temperature [K], (a) northern autumnal equinox $\left(L_{s}=175^{\circ}-185^{\circ}\right)$ and (b) northern winter solstice $\left(L_{s}=265^{\circ}-275^{\circ}\right)$ in the model with TES2 dust scenario. The figures are written by averaging available the same pressure-level temperature data on each grids zonally and eliminating the data at higher pressure than the zonalaveraged value. So are all the following figures which have latitude-altitude profile.

obtained significantly higher dust opacities at southern polar regions during the TES Year 2 dust storm than those of Smith et al. (2001a), who obtained dust opacities that are equal or higher in the tropics than at high latitudes. It is mentioned in Liu et al. (2003) that it is not clear whether their retrievals overestimated, those of Smith et al. (2001a) underestimated or the true opacities lie between these two estimates. Our model results may indicate the overestimate of dust opacity by Liu et al. (2003) retrievals. At the regions above $0.1 \mathrm{hPa}$, the numerical results tend to be cooler than the observations on the whole, around $20 \mathrm{~K}$ at $0.01 \mathrm{hPa}$ except above the equator and summer hemisphere.

Figure 9 shows the numerical results of zonal wind corresponding to Fig. 8. At northern autumn equinox the westerly wind velocity at all altitudes in the northern hemisphere is lower than the observational gradient wind shown in Smith et al. (2001a), because the latitudinal gradient of temperature shown in Fig. 8(a) is not so high as observation. At northern winter solstice the maximum easterly wind velocity reaches more than $160 \mathrm{~m} \mathrm{~s}^{-1}$ above southern low-latitude regions, because of higher latitudinal gradient of temperature which becomes hotter toward south around these regions than observation. Except these points, the results are consistent with the observational gradient wind.

Figure 10 shows the mass stream function corresponding to Figs. 8 and 9. In both equinoxes the profile is near a symmetric circulation with respect to the equator, though below the altitude of $1 \mathrm{hPa}$ an asymmetric pattern with respect to the equator exists, which the intensity of northern circulation is stronger than that of southern circulation. This asymmetric pattern seems to be caused dominantly by the topographic elevation difference between northern and southern hemisphere (Takahashi et al. 2003). In both solstices the characteristic meridional circulation on Mars exists, which flows across the equator from summer hemisphere to winter hemisphere. It also shows that the circulation is $2 \sim 3$ times stronger in southern summer than in northern summer, which is consistent with the results of other Martian GCMs (Haberle et al. 1993; Forget et al. 1999; Richardson and Wilson 2002; Takahashi et al. 2003). The sources of this phenomenon seem to be not only the difference of the amount of insolation as mentioned in Section 1, but also the effects of Martian topography which 
Zonal Wind $\left(\mathrm{m} \mathrm{s}^{-1}\right): \mathrm{Ls}=175^{\circ}-185^{\circ}$

TES2

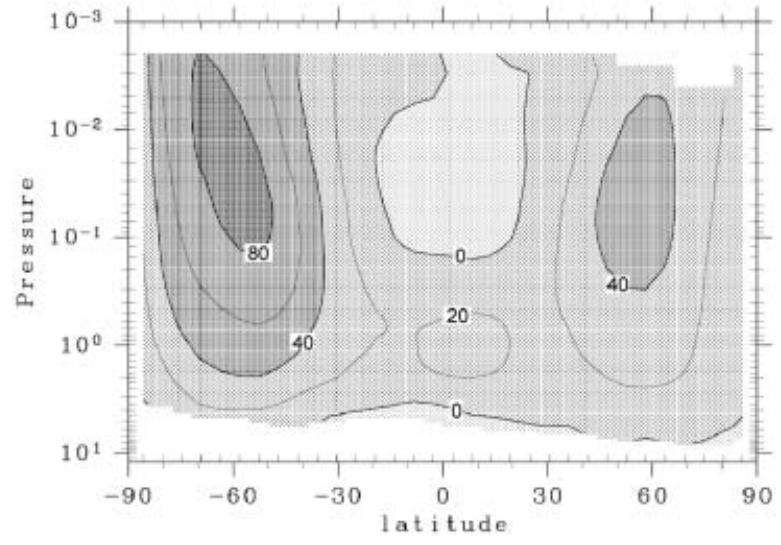

(a)
Zonal Wind $\left(\mathrm{m} \mathrm{s}^{-1}\right): \mathrm{Ls}=265^{\circ}-275^{\circ}$ TES2

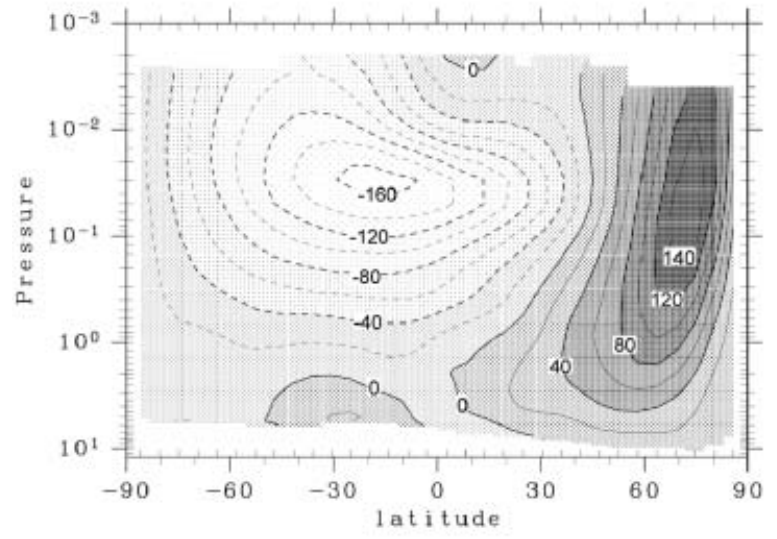

(b)

Fig. 9. Same as Fig. 8, except for zonal wind [m s$\left.{ }^{-1}\right]$.

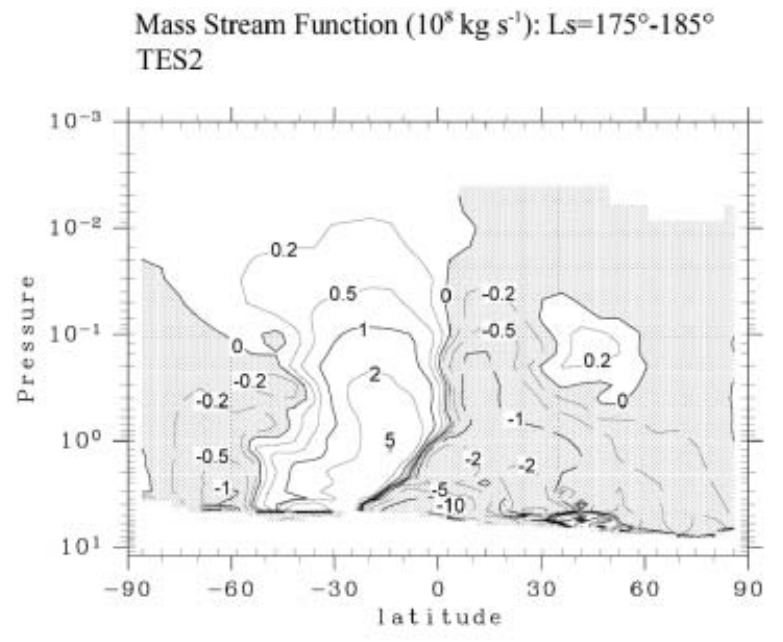

(a)

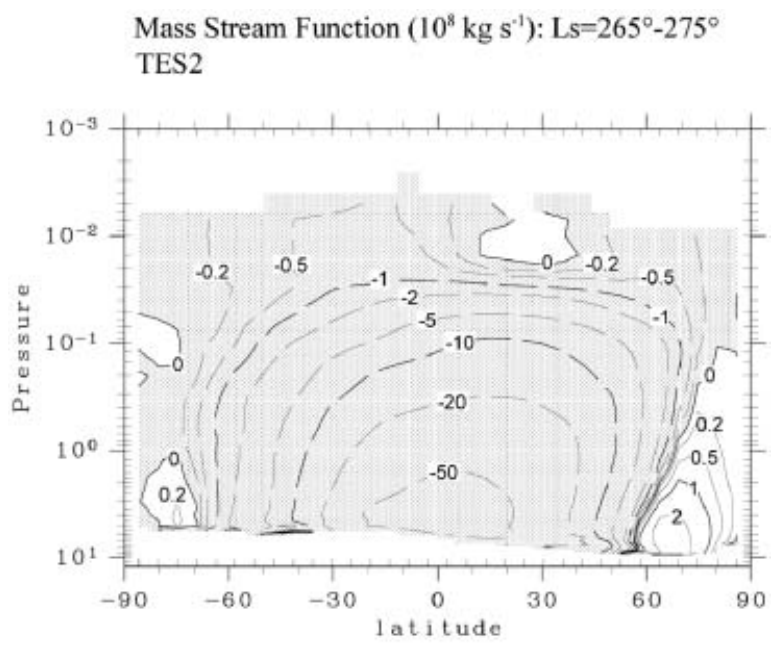

(b)

Fig. 10. Same as Fig. 8, except for mass stream function $\left[10^{8} \mathrm{~kg} \mathrm{~s}^{-1}\right]$.

have global north-to-south elevation (Richardson and Wilson 2002).

\section{1.b Interannual variability between the results of the models with TES2 and TES3 dust scenario}

Figure 11 shows the daytime (local time 1400) zonal-mean temperature distribution in the model with TES3 dust scenario, the difference of the daytime temperature between the models with TES2 and TES3 dust scenarios and the difference of temperature between daytime and nighttime (local time $\sim 0200$ ) in the model with TES3 scenario, at $L_{s}=205^{\circ}$ in the middle of planet-encircling dust storm in the models with TES3 dust scenario. Comparing them with the observational results in TES Year 3 (Smith et al. 2002), the daytime temperature below the altitude of $0.1 \mathrm{hPa}$ is $\sim 10 \mathrm{~K}$ larger around the equator. The difference of the 


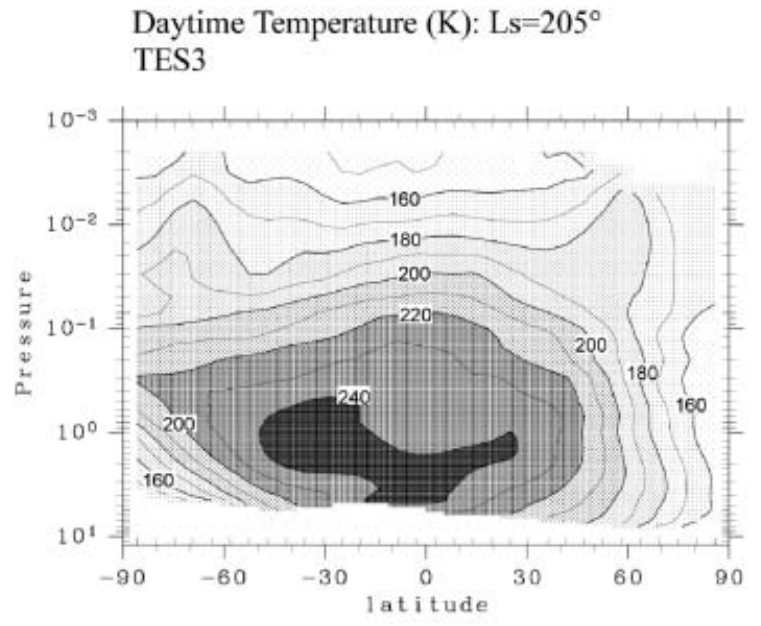

(a)

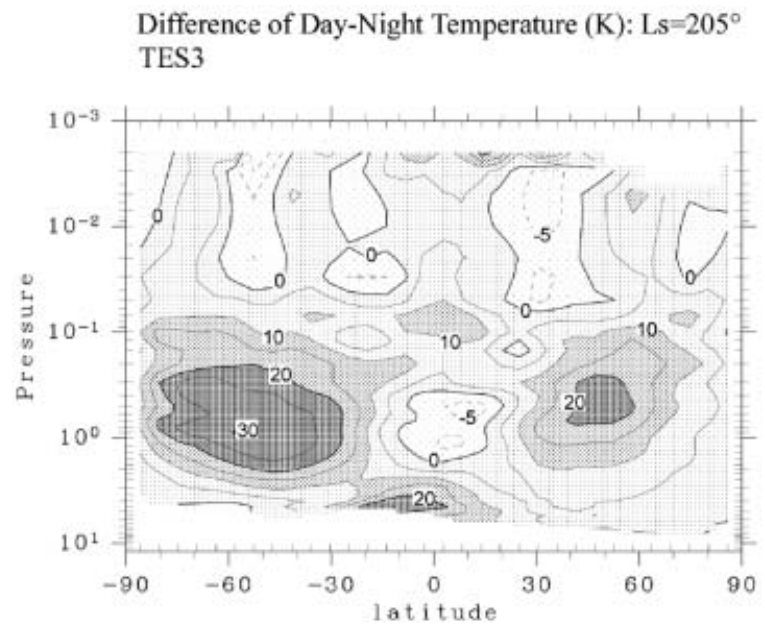

(c)

daytime temperature between the models with TES2 and TES3 dust scenarios is consistent above the south pole, but larger above the equator especially around the altitude of $0.1 \mathrm{hPa}$ $(\sim 25 \mathrm{~K})$. This overestimated heating seems to be due to the vertical distribution of dust, that is, these results indicate that the cut-off altitude of dust around the equator is too high in TES3 dust scenario. The global dust storm in 2001 began soon after the northern autumn equinox, earlier than the global dust storms previously observed by Mariner 9 and Viking Orbiters, when the northward meridional circulation is weaker. This may cause the lower cut-off altitude above the equator during the global dust storm in 2001, than the obser-

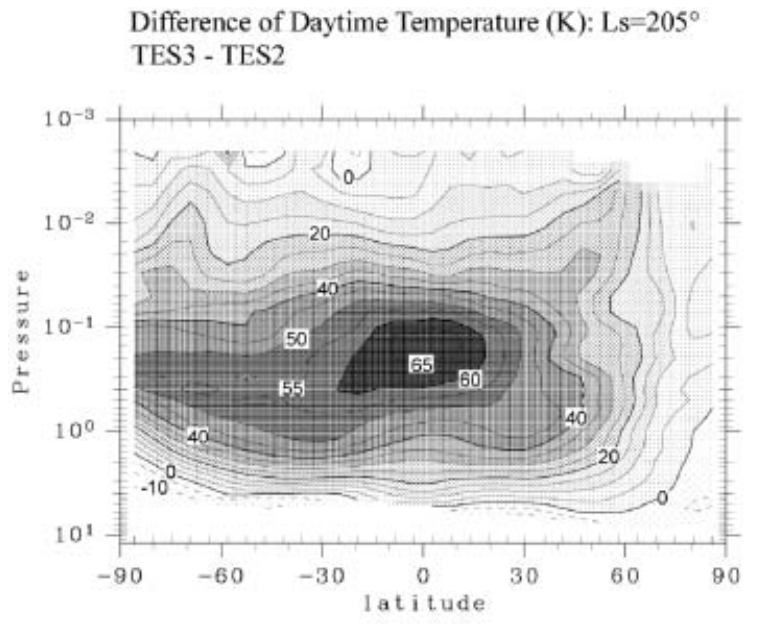

(b)

Fig. 11. Numerical results of zonal-mean thermal structure of the atmosphere at $L_{s}=205^{\circ}$. Three days of data are averaged in each case. (a) Daytime (local time 1400) atmospheric temperature $[\mathrm{K}]$ in the models with TES3 dust scenario. (b) The difference of daytime (local time $\sim 1400$ ) atmospheric temperatures $[\mathrm{K}]$ between the models with TES2 and TES3 dust scenarios, calculated by subtracting results with TES2 from results with TES3. (c) The difference of between daytime (local time $\sim 1400$ ) and nighttime (local time $\sim 0200$ ) temperatures $[\mathrm{K}]$ in the model with TES3 dust scenario, calculated by subtracting nighttime results from daytime results.

vational results of previous global dust storms observed by Mariner 9 and Viking Orbiters (Anderson and Leovy 1978; Jaquin et al. 1986).

The difference of temperature between daytime and nighttime in the model with TES3 dust scenario (Fig. 11(c)) is consistent with the observational result in northern hemisphere, but $\sim 20 \mathrm{~K}$ smaller above southern midlatitude and polar region. This seems to be due to the change of dust opacity between day and night in real Martian atmosphere, which is not considered in our model.

\subsection{Time evolution of $\mathrm{CO}_{2}$ ice}

Figure 12 shows the seasonal variation of surface $\mathrm{CO}_{2}$ ice thickness in the model with 


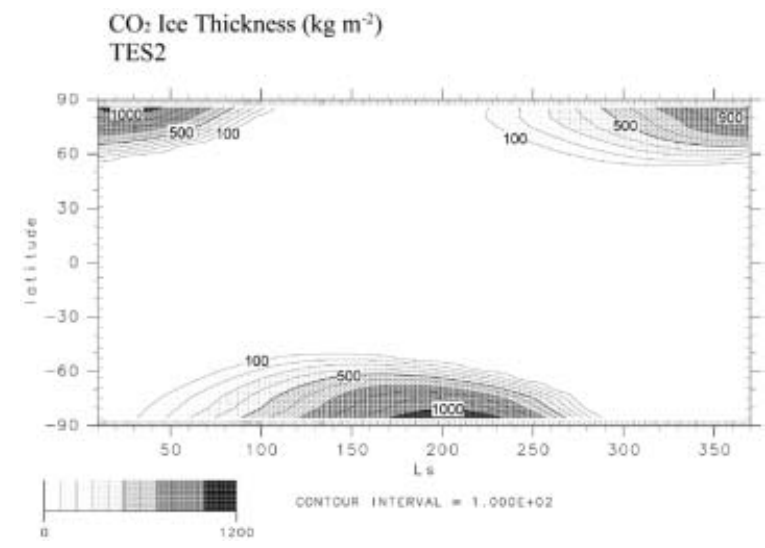

Fig. 12. Numerical results of seasonal cross-section of the zonal-mean thickness of $\mathrm{CO}_{2}$ polar cap $\left[\mathrm{kg} \mathrm{m}^{-2}\right]$ on the surface in the model with TES2 dust scenario.

TES2 dust scenario. The result of this model indicates the maximum zonal-mean ice thickness of both polar regions with $\sim 1100 \mathrm{~kg} \mathrm{~m}^{-2}$ around spring equinoxes of both hemisphere. When we define the density of $\mathrm{CO}_{2}$ cap $910 \mathrm{~kg} \mathrm{~m} \mathrm{~m}^{-3}$, the maximum zonal-mean ice thickness in this model is $\sim 1.2 \mathrm{~m}$, consistent with the observational results of Smith et al. (2001b).

The northern seasonal cap in this model regresses with remaining circular shape during spring, as shown in Fig. 13. But the recession speed is slower than the MOC observational results in 2000 shown by James and Cantor (2001). They indicate the averaged latitude of the edge of north seasonal cap is about $58^{\circ} \mathrm{N}$ at $L_{s}=0^{\circ}, 67^{\circ} \mathrm{N}$ at $L_{s}=40^{\circ}$ and $75^{\circ} \mathrm{N}$ at $L_{s}=70^{\circ}$. The TES observations in 2000 by Kieffer and Titus (2001) indicate almost the same results as the MOC observation. The latitude of the edge indicated by both the amount of seasonal cap (Fig. 13) and the ground temperature in this model is $5-10^{\circ}$ outside of the observational results at all these times.

During the recession of the southern seasonal cap, apparent axiasymmetrical structure of the cap is not seen in this model, even after $L_{s}=240^{\circ}$. The averaged latitude of the edge of the south seasonal cap is about $60^{\circ} \mathrm{S}$ at $L_{s}=219^{\circ}$ and $68^{\circ} \mathrm{S}$ at $L_{s}=245^{\circ}$, which is about $5^{\circ}$ outside of the observational results by Kieffer et al. (2000).

In the models with TES3 and VIK1 dust scenarios, almost the same results as in the model
$\mathrm{CO}_{2}$ Ice Thickness $\left(\mathrm{kg} \mathrm{m}^{-2}\right): \mathrm{Ls}=0^{\circ}$

TES2

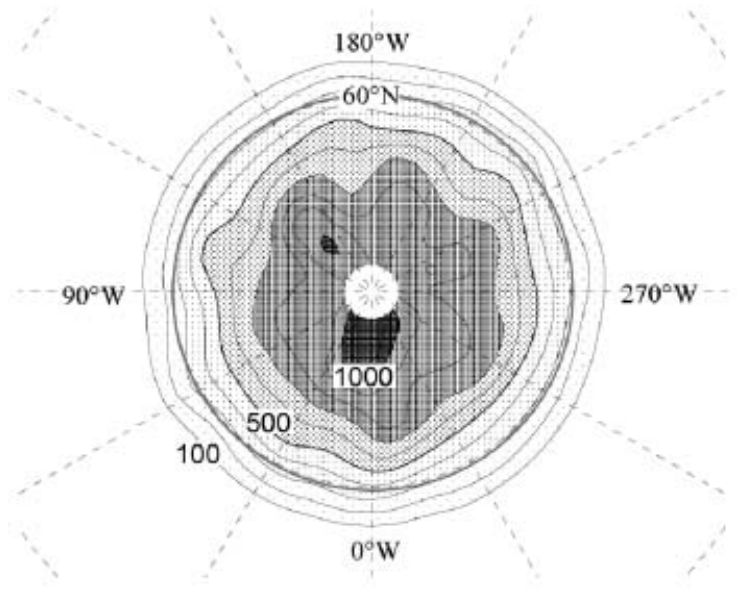

(a)
$\mathrm{CO}_{2}$ Ice Thickness $\left(\mathrm{kg} \mathrm{m}^{-2}\right): \mathrm{Ls}=40^{\circ}$ TES2

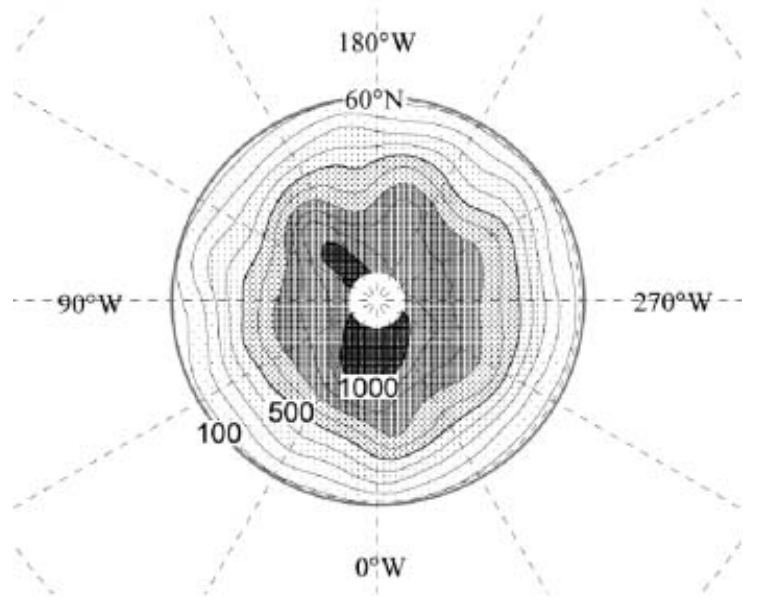

(b)

Fig. 13. Numerical results of the thickness of $\mathrm{CO}_{2}$ polar cap $\left[\mathrm{kg} \mathrm{m}{ }^{-2}\right]$ in north polar region in the model with TES2 dust scenario; (a) at $L_{s}=0^{\circ}$ and (b) at $L_{s}=40^{\circ}$. Solid circle in each figures indicate the latitude of $60^{\circ} \mathrm{N}$. 


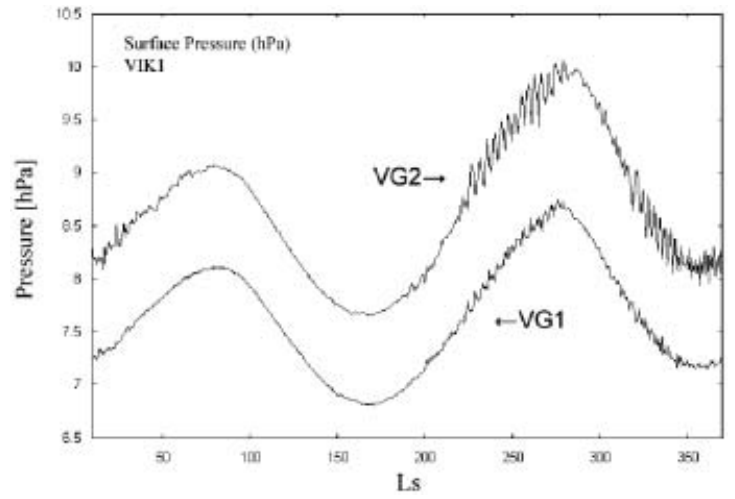

Fig. 14. Numerical results of seasonal cross-section of the surface pressure at VG1 and VG2 in the model with VIK1 dust scenario. Because of the difference of elevation between grid points in the model and lander points $(-3.43$ and $-2.69 \mathrm{~km}$ at Lander $1,-4.43$ and $-4.23 \mathrm{~km}$ at Lander 2), the values are multiplied to the raw model results by 0.93 (VG1) and 0.98 (VG2).

with TES2 dust scenario are obtained, though the thicknesses of seasonal caps in both poles are slightly (less than $50 \mathrm{~kg} \mathrm{~m}^{-2}$ ) thicker. In these models the increase of surface temperature during southern spring and summer is suppressed by large-scale dust storms as compared with TES2 dust scenario, so the polar caps seem to grow easier at the surface.

\subsection{Seasonal pressure variances}

Figure 14 shows the seasonal variation of daily averaged surface pressure values at the nearest grid points of VL1 and VL2 $\left(24.92^{\circ} \mathrm{N}\right.$, $50.62^{\circ} \mathrm{W}$ and $47.07^{\circ} \mathrm{N}, 225.00^{\circ} \mathrm{W}$; hereafter referred to as VG1 and VG2) in the model with VIK1 dust scenario, with modification due to the differences of elevation between grid points in the model and lander points. The pressure at VG1 varies between 6.8 and $8.7 \mathrm{hPa}$ and at VG2 between 7.8 and $10.0 \mathrm{hPa}$. Comparing these results with the observational results by Viking Landers (e.g. Tillman 1988), the numerical result at VG1 is about $0.3 \mathrm{hPa}$ lower at two maximum points $\left(L_{s}=80^{\circ}\right.$ and $\left.L_{s}=270^{\circ}\right)$, $0.7 \mathrm{hPa}$ lower at northern spring minimum point $\left(L_{s}=350^{\circ}\right)$ and consistent at northern autumn minimum point $\left(L_{s}=170^{\circ}\right)$; at VG2 consistent at two maximum points, $0.7 \mathrm{hPa}$ lower at a northern spring minimum point and $0.3 \mathrm{hPa}$ higher at northern autumn minimum point. In northern spring the numerical results become relatively rather low compared to observation, probably because of the excess of northern $\mathrm{CO}_{2}$ polar cap in this model, as mentioned in Subsection 3.2. The synoptic period oscillations attributed to baroclinic waves can be seen conspicuously between northern autumn and spring in the numerical results at both grids, with amplitudes consistent with those observed at both Landers. The synoptic period oscillations reduce significantly at both grids between $L_{s}=280^{\circ}$ and $L_{s}=310^{\circ}$, when the second planet-encircling dust storm is occurring, as seen in the observational results. In this period the temperature at the altitude of $0.5 \mathrm{hPa}$ above VG1 and VG2 becomes very high (more than $230 \mathrm{~K}$ ) in the model, which seems to result in high static stability of atmosphere and the reduction of baloclinic waves. Spectral analyses of these synoptic period oscillations are made in Subsection 3.5.

In the model with TES3 dust scenario the surface pressures at VG1 and VG2 become $\sim 0.1 \mathrm{hPa}$ lower than in the model with VIK1 dust scenario between $L_{s}=190^{\circ}$ and $L_{s}=300^{\circ}$, because of the increase of polar caps by the suppression of surface temperature as mentioned in Subsection 3.2. In reverse the surface pressures in the model with TES3 dust scenario become $\sim 0.1 \mathrm{hPa}$ higher than in the model with VIK1 dust scenario between $L_{s}=320^{\circ}$ and $L_{s}=100^{\circ}$, because of the suppression of surface temperature in the model with VIK1 dust scenario by the second global dust storm. In the model with TES2 dust scenario the lower surface pressures between $L_{s}=190^{\circ}$ and $L_{s}=300^{\circ}$ are not seen, and only the higher pressures between $L_{s}=320^{\circ}$ and $L_{s}=100^{\circ}$ are seen. In both the model with TES2 and TES3 dust scenarios, the reductions of oscillations between $L_{s}=280^{\circ}$ and $L_{s}=310^{\circ}$ are not seen.

\subsection{Diurnal and semidiurnal thermal tides}

Figure 15 shows the seasonal variances of the amplitudes of diurnal and semidiurnal surface pressure oscillations in the model with VIK1 dust scenario, expressed as percent of the mean pressure at VG1. This figure is made with 1-hour-mean numerical results of surface 


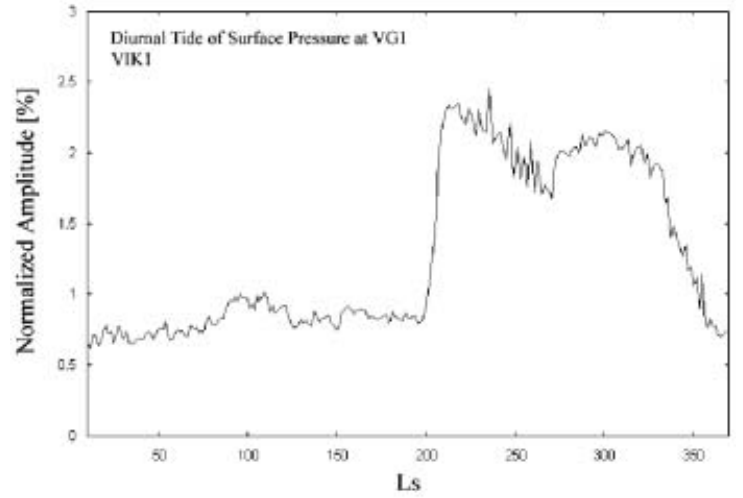

(a)

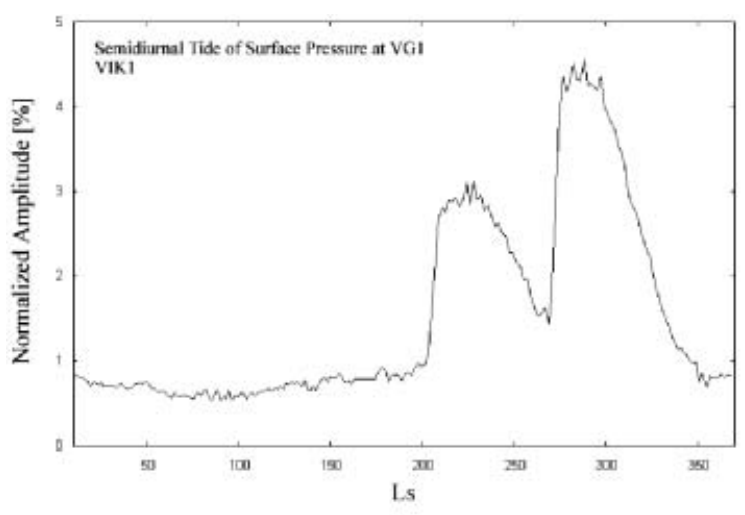

(b)

Fig. 15. The simulated amplitudes of (a) diurnal and (b) semidiurnal surface pressure oscillations at VG1 in the model with VIK1 dust scenario, expressed as percent of the mean pressure.

pressure. The simulated amplitudes in northern spring and summer, when without global dust storms, are 0.7-1.0 percent in diurnal and 0.6-0.8 percent in semidiurnal, which are slightly smaller than observation by VL1 (e.g. Leovy and Zurek 1979). The amplitudes at VG1 become large during two global dust storms, with the maximum values of 2.4 and 2.2 percent in diurnal and 3.0 and 4.5 percent in semidiurnal. These results are $0.2-0.8$ percent smaller than observation, except semidiurnal second maximum ( 0.5 percent larger). This shows that the global dust storms increase the amplitudes 3-6 times in the model, being consistent with observational results, though semidiurnal tide during second planet-encircling dust storm seems to be too large.
In also the model with TES2 dust scenario, which has much smaller dust opacity than VIK1 dust scenario during northern autumn and winter, the amplitudes of diurnal and semidiurnal tide increase as dust opacity increases, but the maximum amplitudes are 1.8 percent in diurnal and 1.7 percent in semidiurnal. These values are at most 2.5 times of those in northern spring and summer. In the model with TES3 dust scenario the maximum amplitudes are 2.5 percent in diurnal and 3.0 percent in semidiurnal, which are almost the same as during first dust storm in the model with VIK1 dust scenario.

\subsection{Baroclinic waves}

As referred in Subsection 3.3, the oscillations with the period of longer than 1 Sol in northern midlatitude winter are reproduced in our model. So we performed the spectral analyses of the numerical results of surface pressure and meridional wind at VG2 in the model with VIK1 dust scenario choosing three time periods; 1) $L_{s}=210^{\circ}-255^{\circ}$ (hereafter autumn, 70 Sols), 2) $L_{s}=280^{\circ}-313^{\circ}$ (hereafter winter, 54 Sols) and 3) $L_{s}=325^{\circ}-0^{\circ}$ (hereafter spring, 65 Sols). The spectra are made with 1-hour-mean numerical results of surface pressure and meridional wind at the lowest layer ( $\sim 5 \mathrm{~m}$ height).

In the autumn period, as shown in Fig. 16, a peak centered at the frequency (hereafter $f$ ) of 0.16 (a period of 6.4 Sols) is very evident in both variables. The second evident peak in the meridional wind spectra is seen centered at $f=0.29$ (3.5 Sols), where a small peak is seen also in the pressure spectra. In both variables minor peaks centered at $f=0.39$ (2.6 Sols), $f=0.44(2.3$ Sols $)$ and $f=0.50(2.0$ Sols $)$ are also seen. There are some additional peaks with the period of shorter than 2 Sols $(f>0.50)$ in only the meridional wind spectra.

In the winter period, as shown in Fig. 17, in the pressure spectra an evident peak is seen only centered at $f=0.22$ (4.5 Sols). In the meridional wind spectra there are also peaks centered at $f=0.37$ (2.7 Sols) and $f=0.47$ (2.1 Sols), where slight peaks can be seen also in the pressure spectra, and others. The amplitudes of the peaks in both peaks become significantly smaller than in autumn and spring periods.

In the spring period, as shown in Fig. 18, peaks centered at $f=0.18$ (5.6 Sols) and at 


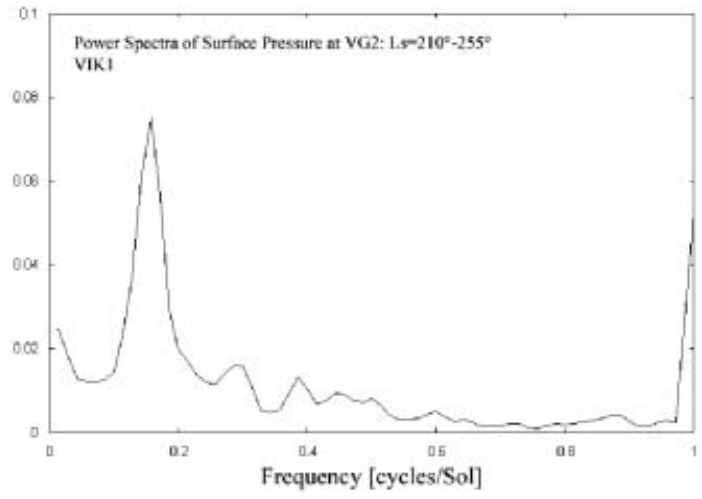

(a)

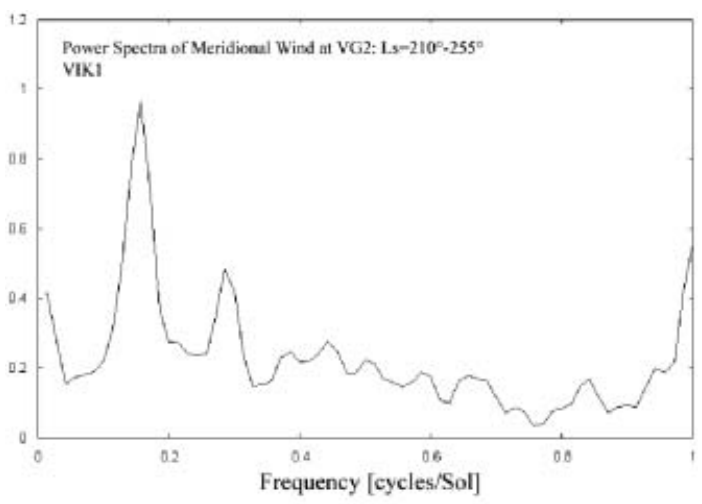

(b)

Fig. 16. The spectra of (a) surface pressure and (b) meridional wind at the lowest layer at VG2 in the model with VIK1 dust scenario in the autumn pe$\operatorname{riod}\left(L_{s}=210^{\circ}-255^{\circ}\right)$. The power spectral density values are given as the variance per unit angular frequency interval, where the pressure unit is $\mathrm{hPa}$ and the wind $\mathrm{m} \mathrm{s}^{-1}$.

$f=0.32$ (3.1 Sols) are very evident in both variables. Other peaks seen evidently in both variables are centered at $f=0.25$ (4.1 Sols), $f=0.42$ (2.4 Sols), $f=0.48$ (2.1 Sols) and $f=0.67$ (1.5 Sols). There are also some additional peaks evident only in the meridional wind spectra with the period of shorter than 2 Sols, as well as in the autumn period. The existence of these high-frequency peaks seen only in the wind spectra would be due to the motions associated with small horizontal scales which may be nongeostrophic (Barnes 1980).

Table 2 shows planetary zonal wave numbers and phase speeds of the peaks evident

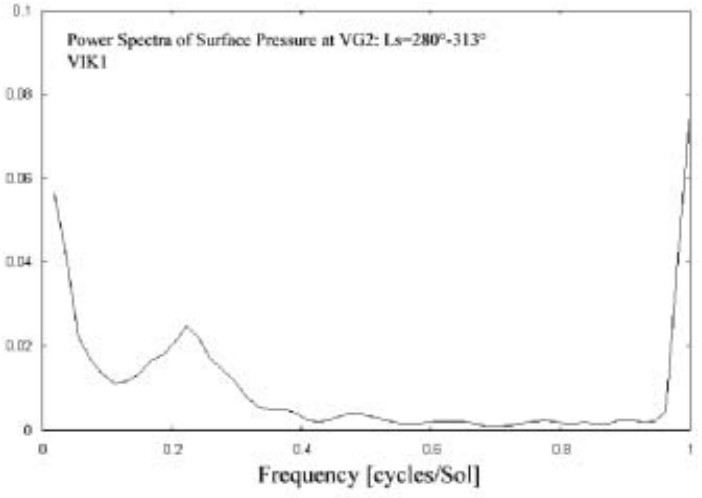

(a)

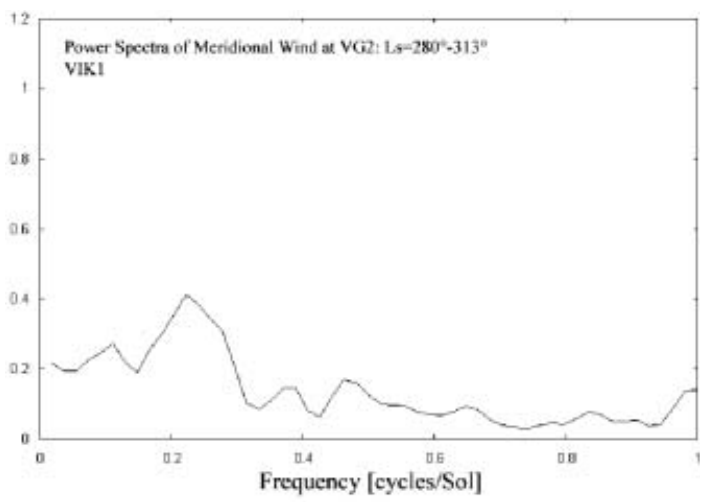

(b)

Fig. 17. Same as Fig. 16, except in the winter period $\left(L_{s}=280^{\circ}-313^{\circ}\right)$.

in both spectra. We calculated them with the geostrophic-balance formula (Ryan et al. 1978; Barnes 1980);

$$
\lambda=2 \pi \frac{R T}{f p} \cdot \frac{p^{\prime}}{v_{g}^{\prime}}
$$

where $\lambda$ is the wavelength, $T$ and $p$ the mean temperature and pressure respectively, $f$ the normal Coriolis parameter, $R$ the gas constant, $p^{\prime}$ the amplitude of the surface pressure perturbation and $v_{g}^{\prime}$ the amplitude of the geostrophic meridional wind perturbation. We define $v_{g}^{\prime}$ using the amplitude of the meridional wind at the lowest layer $v_{1}^{\prime}$ as $v_{g}^{\prime}=2.0 v_{1}^{\prime}$, as determined in Leovy (1979). Note that in this calculation we define the constant value of the geostrophic wind scaling factor and a turning angle of zero.

In the autumn, all the five evident waves have wavenumbers between 1.7 and 4.1, which 


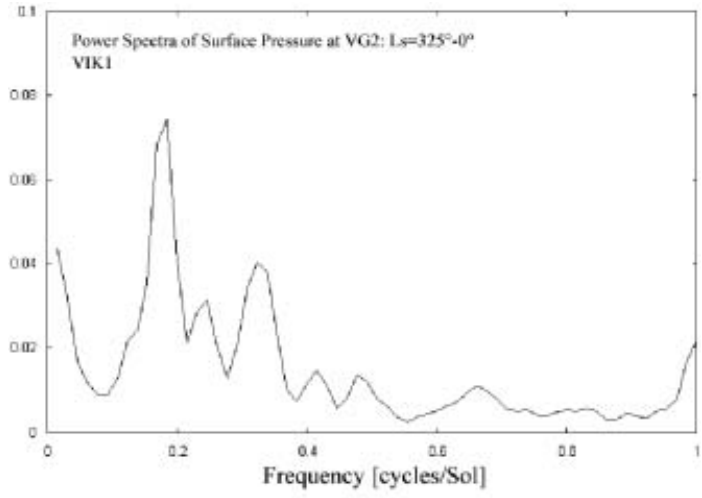

(a)

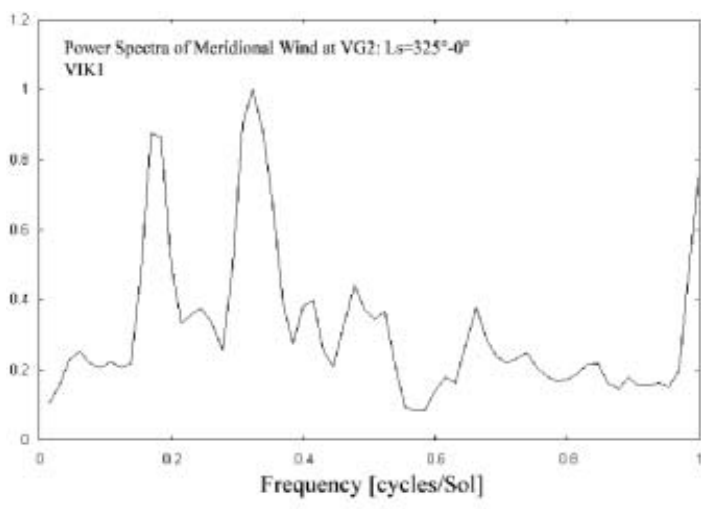

(b)

Fig. 18. Same as Fig. 16, except in the spring period $\left(L_{s}=325^{\circ}-0^{\circ}\right)$.

is roughly consistent with the observational results of the fall period in Barnes (1980). Especially the one which is the most evident in this period (the period of 6.4 Sols) is very consistent in both wavenumber and phase speed with the 6.7-Sols-period wave of observation, which has wavenumber of 1.6 and phase speed of $14.9 \mathrm{~m} \mathrm{~s}^{-1}$. Other evident waves have phase speeds between 11.3 and $24.5 \mathrm{~m} \mathrm{~s}^{-1}$, the values which are consistent with or somewhat faster than observation.

In the winter, the phase speeds of all the three evident waves are between 11.0 and $13.7 \mathrm{~m} \mathrm{~s}^{-1}$, which are not so slow as the observational results of winter period (5.5 and $7.9 \mathrm{~m} \mathrm{~s}^{-1}$ ). The wavenumbers of the two minor waves are consistent with observation, though the most evident wave (the period of 4.5 Sols) has wavenumber of 2.7. In this period the mean zonal wind at the lowest layer in the model is
Table 2 Planetary zonal wavenumbers and phase speeds in the autumn $\left(L_{s}=210^{\circ}-255^{\circ}\right)$, winter $\left(L_{s}=280^{\circ}-\right.$ $\left.313^{\circ}\right)$ and spring $\left(L_{s}=325^{\circ}-0^{\circ}\right)$ periods calculated from pressure and meridional wind spectra at VG2 in the model with VIK1 dust scenario.

\begin{tabular}{|c|c|c|}
\hline $\begin{array}{c}\text { Time and } \\
\text { Period [sols] }\end{array}$ & Wavenumber & $\begin{array}{c}\text { Phase speed } \\
{\left[\mathrm{m} \mathrm{s}^{-1}\right]}\end{array}$ \\
\hline Autumn, 6.4 & 1.7 & 14.7 \\
Autumn, 3.5 & 4.1 & 11.3 \\
Autumn, 2.6 & 2.6 & 24.5 \\
Autumn, 2.3 & 4.0 & 18.1 \\
Autumn, 2.0 & 3.8 & 21.5 \\
\hline Winter, 4.5 & 2.7 & 13.7 \\
Winter, 2.7 & 4.6 & 13.0 \\
Winter, 2.1 & 7.0 & 11.0 \\
\hline Spring, 5.6 & 1.4 & 20.2 \\
Spring, 4.1 & 1.5 & 27.5 \\
Spring, 3.1 & 3.0 & 17.5 \\
Spring, 2.4 & 3.3 & 20.7 \\
Spring, 2.1 & 4.0 & 19.6 \\
Spring, 1.5 & 4.2 & 26.0 \\
\hline
\end{tabular}

westerly stronger than in autumn and spring, as opposed to observational results, which may result in the faster phase speeds.

In the spring, all the six evident waves have wavenumbers between 1.4 and 4.2 , which are almost the same as in the autumn. The phase speeds of all the waves are more than $17.5 \mathrm{~m} \mathrm{~s}^{-1}$, which are rather fast compared with the observational results. The especially evident two waves, which have the periods of 5.6 and 3.1 sols, have phase speeds which are relatively near the observation, 20.2 and $17.5 \mathrm{~m} \mathrm{~s}^{-1}$, relatively.

\section{Conclusions}

We have constructed a new Mars climate model based on the CCSR/NIES terrestrial AGCM. To simulate the environment of Mars, we have included the realistic surface data of Mars, condensation and sublimation processes of $\mathrm{CO}_{2}$ occurring mainly in polar regions and radiative effects of $\mathrm{CO}_{2}$, considering absorption of solar radiation in the near-IR bands. We also changed radiative processes of atmospheric dust with observed refractive indices and size distribution of Martian dust, and attempted to reproduce the Martian climate observed by 
MGS and Viking by introducing three types of the quantitatively-consistent time- and latitude-dependent dust distribution with the retrieved observational results by Liu et al. (2003). As a result, the model can generally reproduce the distributions and seasonal variations of temperature and zonal wind observed by Mars Global Surveyor in 1999, especially at low altitude regions (below $\sim 0.1 \mathrm{hPa}$ ). The model results of temperature tend to be lower than observation at high altitude (above $\sim 0.1 \mathrm{hPa}$ ). We have three thinkable reasons for this. One may be that the radiative effects of water ice and vapor are not included, because in LMD/AOPP Martian GCM the temperature at high altitude is lower than observation (Forget et al. 2001). Another may be that the radiation code used in calculating the radiative effects of $\mathrm{CO}_{2}$ strong $15 \mu \mathrm{m}$ band is the default code of CCSR/NIES AGCM, which is made to be optimum for the troposphere of Earth, so it may have errors for the cooling rate of thin atmosphere. The third may be the lack of the effects of gravity wave drag, which would strengthen the diabatic forcing of circulation and increase the polar temperature above the altitude of $20 \mathrm{~km}$ in $\sim 10 \mathrm{~K}$ (Forget et al. 1999). The numerical results of the mass stream function are consistent with the results of other Martian GCMs. The reproduction of the effects of a planet-encircling dust storm in 2001 had errors of overestimation of heating at the tropics, and underestimation of the day-night difference of temperature in southern hemisphere. To correct them, the revision of vertical distribution of dust and the consideration of the difference of day-night dust opacity may be needed.

As for the surface processes, the zonal-mean thickness of $\mathrm{CO}_{2}$ seasonal cap in polar regions is calculated as the maximum value of $\sim 1.2 \mathrm{~m}$ in TES2 scenario, which is consistent with the observational results by MGS-MOLA in 1999 and 2000. The edge of the northern and southern seasonal caps are outside of the observational results by MGS-MOC and MGS-TES in 1999 and 2000 during both springs. This seems to result in rather low surface pressure especially in northern spring. The shapes of regressing seasonal caps at both poles roughly remain circular until extinction, which is not consistent with the observational result at the south pole. Further sophistication of the surface model should be expected to improve them.

The diurnal and semidiurnal tides of surface pressure become 3-6 times larger during planet-encircling dust storms than northern spring and summer at VG1 in the model with VIK1 dust scenario, which is consistent with the observational results though semidiurnal tide during the second planet-encircling dust storm is rather large. The amplitudes of the tides are $70-90 \%$ of the observation on the whole.

The synoptic period oscillations attributed to baroclinic waves can be seen conspicuously in the model between northern autumn and spring. In the model with VIK1 dust scenario the oscillations reduce significantly during the planet-encircling dust storm after the winter solstice, as seen in the observation by Viking Landers in 1977. In the spectral analyses of baroclinic waves at VG2 in the model with VIK1 dust scenario, the periods, wavenumbers and phase speeds of the waves in the autumn period are roughly consistent with the observational results by Viking Lander 2 in 1977. In the winter period during the planet-encircling dust storm, the wave with larger wavenumber than in autumn also exists, though the phase speeds of the waves are not so slow as observation. In the spring period, the phase speeds of the waves become rather fast compared with the observation.

The occurring time and intensity of dust storms during northern autumn and winter are characteristic in every Martian year, and according to them Martian climate conditions also differ in every year. Other than thermal tides and baroclinic waves observed by Viking Landers, which we inspected how the model reproduces in the model in this paper, global analyses of thermal tides and associated forced waves with the observational data by MGS have been performed (Banfield et al. 2003; Hinson et al. 2001). It will be our important subject to inspect them in our model, in order to discuss the justice of the model and improve it. We have still a lot of things to bring our Martian AGCM to be sophisticated and reliable.

\section{Acknowledgements}

The authors are grateful to Dr. Masayuki Takigawa for teaching the contents and how 
to improve the CCSR/NIES AGCM, providing topographic data of Mars for our GCM and supplying much information. Also to Dr. Tatsuya Nagashima and Dr. Kengo Sudo for advise for proceeding this study, and to Dr. Naoki Sato for providing programs for spectral analyses.

\section{References}

Anderson, E. and C. Leovy, 1978: Mariner 9 television limb observation of dust and ice hazes on Mars. J. Atmos. Sci., 35, 723-734.

Banfield, D., B.J. Conrath, M.D. Smith, P.R. Christensen and R.J. Wilson, 2003: Forced waves in the Martian atmosphere from MGS TES nadir data. Icarus, 161, 319-345.

Barnes, J.R., 1980: Time spectral analysis of midlatitude disturbances in the Martian atmosphere. J. Atmos. Sci., 37, 2002-2015. 1981: Midlatitude Disturbances in the Martian Atmosphere: A Second Mars Year. J. Atmos. Sci., 38, 225-234.

—, R.M. Haberle, J.B. Pollack, H. Lee and J. Schaeffer, 1996: Mars atmospheric dynamics as simulated by the NASA/Ames general circulation model, 2, winter quasi-stationary eddies. J. Geophys. Res., 101, 12753-12776.

—, J.B. Pollack, R.M. Haberle, R.W. Zurek, C.B. Leovy, H. Lee and J. Schaeffer, 1993: Mars atmospheric dynamics as simulated by the NASA/Ames general circulation model, 2, Transient baroclinic eddies. J. Geophys. Res., 98, 3125-3148.

Cantor, B.A., M.J. Wolff, P.B. James and E. Higgs, 1998: Regression of Martian north polar cap: 1990-1997 Hubble Space Telescope observations. Icarus, 136, 175-191.

Collins, M., S.R. Lewis, P.L. Read and F. Hourdin, 1996: Baroclinic wave transitions in the Martian atmosphere. Icarus, 120, 344-357.

Conrath, B.J., 1975: Thermal structure of the Martian atmosphere during the dissipation of the dust storm of 1971. Icarus, 24, 36-46.

, J.C. Pearl, M.D. Smith, W.C. Maguire, P.R. Christensen, S. Dason and M.S. Kaelberer, 2000: Mars Global Surveyor Thermal Emission Spectrometer (TES) observations: Atmospheric temperatures during aerobraking and science phasing. J. Geophys. Res., 105, 9509-9519.

Forget, F., 1998: Improved optical properties if the Martian atmospheric dust for radiative transfer calculations in the infrared. Geophys. Res. Lett., 25, 1105-1108.

, M. Angelates I Coll, Y. Wanherdrick, F. Hourden, S. Lewis, P. Read, F. Taylor, M. Lopez-Valverde and M. Lopez-Puertas, 2003: Modeling of the General Circulation with the
LMD-AOPP-IAA GCM: Update on Model Design and Comparison with Observations, Abstract of "Mars atmosphere modelling and observations", Granada, Spain, 6 pp.

, F. Hourdin and O. Talagrand, 1998: $\mathrm{CO}_{2}$ Snowfall on Mars: Simulation with a General Circulation Model. Icarus, 131, 302-316.

,,-- R. Fournier, C. Hourdin and O. Talagrand, 1999: Improved general circulation models of the Martian atmosphere from the surface to above $80 \mathrm{~km}$. J. Geophys. Res., 104, 24155-24175.

—, Y. Wanherdrick and S.R. Lewis, 2001: Validation of the Mars General Circulation Model and Climate Database with new spacecraft observations, European Space Agency Technical Report, 22 pp.

Haberle, R.M., M.M. Joshi, J.R. Murphy, J.R. Barnes, J.T. Schofield, G. Wilson, M. LopezValverde, J.L. Hollingsworth, A.F.C. Bridge and J. Schaeffer, 1999: General circulation model simulations of the Mars Pathfinder atmospheric structure investigation/meteorology data. J. Geophys. Res., 104, 8957-8974. , J.B. Pollack, J.R. Barnes, R.W. Zurek, C.B. Leovy, J.R. Murphy, H. Lee and J. Schaeffer, 1993: Mars atmospheric dynamics as simulated by the NASA/Ames general circulation model, 1, the zonal-mean circulation. J. Geophys. Res., 98, 3093-3124.

Hinson, D.P., G.L. Tyler, J.L. Hollingsworth and R.J. Wilson, 2001: Radio occultation measurements of forced atmospheric waves on Mars. J. Geophys. Res., 106, 1463-1480.

Hourdin, F., F. Forget and O. Talagrand, 1995: The sensitivity of the Martian surface pressure to various parameters: A comparison between numerical simulations and Viking observations. J. Geophys. Res., 100, 5501-5523.

- , P. Le Van, F. Forget and O. Talagrand, 1993: Meteorological variability and the annual surface pressure cycle on Mars. J. Atmos. Sci., 50, 3625-3640.

James, P.B. and B.A. Cantor, 2001: Martian north polar cap recession: 2000 Mars Orbiter Camera observations. Icarus, 154, 131-144.

-, H.H. Kieffer and D.A. Paige, 1992: The seasonal cycle of carbon dioxide on Mars, in Mars, edited by H.H. Kieffer et al., Univ. of Ariz. Press, Tucson, 934-968 pp.

Jaquin, F., P. Gierasch and R. Kahn, 1986: The vertical structure of limb hazes in the Martian atmosphere. Icarus, 68, 442-461.

Kieffer, H.H. and T.N. Titus, 2001: TES mapping of Mars' north seasonal cap. Icarus, 154, 162180. K.F. Mullins and P.R. Christensen, 
2000: Marth south polar spring and summer behavior observed by TES: Seasonal cap evolution controlled by frost grain size. J. Geophys. Res., 105, 9653-9699.

Larsen, J. and D. Dahl-Jensen, 2000: Interior temperatures of the northern polar cap on Mars. Icarus, 144, 456-462.

Leovy, C.B., 1969: Mars: Theoretical aspects of meteorology. Appl. Opt., 8, 1279-1286.

- 1979: Martian meteorology. Ann. Rev. Astron. Astrophys., 17, 387-413.

- 1981: Observations of Martian tides over two annual cycles. J. Atmos. Sci., 38, 30-39.

- and Y. Mintz, 1969: Numerical simulation of the atmospheric circulation and climate of Mars. J. Atmos. Sci., 26, 1167-1190.

and R.W. Zurek, 1979: Thermal tides and Martian dust storms: Direct evidence for coupling. J. Geophys. Res., 84, 2956-2968.

Lewis, S.R., M. Collins and F. Forget, 2001: Mars Climate Database v3.0 Detailed Design Document, European Space Agency Technical Report, $29 \mathrm{pp}$.

$\longrightarrow,-$ P.L. Read, F. Forget, F. Hourdin, R. Fournier, C. Hourdin, O. Talagrand and J.-P. Huot, 1999: A climate database for Mars. J. Geophys. Res., 104, 24177-24194.

Liu, J., M.I. Richardson and R.J. Wilson, 2003: An assessment of the global, seasonal, and interannual spacecraft record of Martian climate in the Thermal infrared. J. Geophys. Res., 108(E8), 10.1029/2002JE001921.

Lopez-Puertas, M. and M.A. Lopez-Valverde, 1995: Radiative Energy Balance of $\mathrm{CO}_{2}$ Non-LTE Infrared Emissions in the Martian Atmosphere. Icarus, 114, 113-129.

Lopez-Valverde, M.A., D.P. Edwards, M. LopezPuertas and C. Roldan, 1998: Non-local thermodynamic equilibrium in general circulation models of the Martian atmosphere 1. Effects of the local thermodynamic equilibrium approximation on thermal cooling and solar heating. $J$. Geophys. Res., 103, 16799-16811.

Martin, T.Z., 1986: Thermal infrared opacity of the Mars atmosphere. Icarus, 66, 2-21.

and M.I. Richardson, 1993: New dust opacity mapping from Viking infrared thermal mapping data. J. Geophys. Res., 98, 10941-10949.

Mellon, M.T., 2001: Thermal Inertia and Rock Abundance, Abstract of "Exploring Mars with TES: A Data User's Workshop", Tempe, Arizona, $6 \mathrm{pp}$.

Nakajima, T. and M. Tanaka, 1986: Matrix formulations for the transfer of solar radiation in a plane-parallel scattering atmosphere. $J$. Quant. Spectrosc. Radiat. Transfer, 35, 13-21.

Numaguti, A., 1993: Dynamics and energy balance of the Hadley circulation and the tropical precipitation zones: Significance of the distribution of evaporation. J. Atmos. Sci., 50, 1874-1887.

, M. Takahashi, T. Nakajima and A. Sumi, 1995: Development of atmospheric general circulation model, in Climate System Dynamics and Modeling, edited by T. Matsuno, Center for Climate System Research, University of Tokyo, Tokyo, 1-27.

Ockert-Bell, M.E., J.F. Bell III, J.B. Pollack, C.P. McKay and F. Forget, 1997: Absorption and scattering properties of the Martian dust in the solar wavelengths. J. Geophys. Res., 102, 9039-9050.

Pollack, J.B., R.M. Haberle, J. Schaeffer and H. Lee, 1990: Simulations of the general circulation of the Martian atmosphere, 1 , Polar processes. $J$. Geophys. Res., 95, 1447-1473.

, J.R. Murphy, J. Schaeffer and H. Lee, 1993: Simulation of the general circulation of the Martian atmosphere 2, Seasonal pressure variations. J. Geophys. Res., 98, 3149-3181.

- C.B. Leovy, P.W. Greiman and Y. Mintz, 1981: A Martian general circulation experiment with large topography. J. Atmos. Sci., 38, 3-29.

Richardson, M.I. and R.J. Wilson, 2002: A topographically forced asymmetry in the Martian circulation and climate. Nature, 416, 298-301.

Ryan, J.A., R.M. Henry, S.L. Hess, C.B. Leovy, J.E. Tillman and C. Walcek, 1978: Mars meteorology: Three seasons at the surface. Geophys. Res. Lett., 5, 715-718.

Sharman, R.D. and J.A. Ryan, 1980: Mars atmospheric pressure periodicities from Viking observation. J. Atmos. Sci., 37, 1994-2001.

Smith, D.E., M.T. Zuber, S.C. Solomon, R.J. Phillips, J.W. Head, J.B. Garvin, W.B. Banerdt, D.O. Muhleman, G.H. Pettengill, G.A. Neumann, F.G. Lemoide, J.B. Abshire, O. Aharonson, C.D. Brown, S.A. Hauck, A.B. Ivanov, P.J. McGovern, H.J. Zwally and T.C. Duxbury, 1999: The global topography of Mars and implications for surface evolution. Science, 284, 14951503.

Smith, M.D., B.J. Conrath, J.C. Pearl and P.R. Christensen, 2002: NOTE Thermal Emission Spectrometer observations of Martian planetencircling dust storm 2001A. Icarus, 157, 259263.

strument and Thermal Structure Observations, Abstract of "Mars atmosphere modelling and observations", Granada, Spain, 4 pp. , J.C. Pearl, B.J. Conrath and P.R. Christensen, 2001a: Thermal Emission Spectromter 
results: Mars atmospheric thermal structure and aerosol distribution. J. Geophys. Res., 106, 23929-23945.

Smith, D.E., M.T. Zuber and G.A. Neumann, 2001b: Seasonal variations of snow depth on Mars. Science, 294, 2141-2146.

Takahashi, Y.O., H. Fujiwara, H. Fukunishi, M. Odaka, Y.-Y. Hayashi and S. Watanabe, 2003: Topographically induced north-south asymmetry of the meridional circulation in the Martian atmosphere. J. Geophys. Res., 108(E3), 10.1029/2001JE001638.

Tillman, J.E., 1988: Mars global atmospheric oscillations: Annually synchronized, transient normal-mode oscillations and the triggering of global dust storms. J. Geophys. Res., 93, 94339451.
Tomasko, M.G., L.R. Doose, M. Lemmon, P.H. Smith and E. Wegryn, 1999: Properties of dust in the Martian atmosphere from the Imager on Mars Pathfinder. J. Geophys. Res., 104, 8987-9007.

Toon, O.B., J.B. Pollack and C. Sagan, 1977: Physical Properties of the Particles Composing the Martian Dust Storm of 1971-1972. Icarus, 30, 663-696.

Wilson, R.J. and K. Hamilton, 1996: Comprehensive model simulation of thermal tides in the Martian atmosphere. J. Atmos. Sci., 53, 12901326.

and M.I. Richardson, 2000: The Martian atmosphere during the Viking Mission, I: Infrared measurements of atmospheric temperatures revisited. Icarus, 145, 555-579. 